APLL Advances in Peer-Led Learning

$\begin{array}{lll}\text { Number } 1 & \text { Fall } 2021 & \text { Article } 10\end{array}$

\title{
Active Learning with Silent Participation
}

A.E. Dreyfuss

Learning Developer

aedreyfuss@aol.com

\section{Recommended Citation}

Dreyfuss, A.E. (2021). Active Learning with Silent Participation. Advances in Peer-Led Learning, 1, 110-121. Online at https:// doi.org/10.54935/apll2021-01-10-110 
APLL Advances in Peer-Led Learning

\title{
Active Learning with Silent Participation
}

\author{
A.E. Dreyfuss \\ Learning Developer \\ aedreyfuss@aol.com
}

\begin{abstract}
Silence by participants in peer-led learning sessions is often viewed as lack of engagement and interpreted as lack of participation or interest. This paper addresses facets of silence, suggesting linguistic, cultural, and other reasons for quietude, and provides methods of facilitation that incorporate silence to give voice to noiseless participation as a bridge to learning.
\end{abstract}

Keywords: Silent Participation, Facilitation, Communication, Interaction, Engagement, Peer-led Team Learning 
A brief meditation on facets of silence

Silence -- The void of noise, the absence of sound.

A moment of silence: This can be a time of reflection, alone with one's thoughts, taking stock of one's inner voice. Silence is also a means of creating space, perhaps in a religious context, intentional.

Silence can be fruitful, a natural pause in a conversation, a time to gather one's thoughts: companionable silence, welcome silence. Or silence can be an oxymoron: "Deafening silence," which suggests resistance, a reaction to something that has been introduced and is rejected. Or "deathly silence," where there is a tautness, or discomfort in a specific setting or again, resistance or rejection. There is a cultural acceptance of ignoring the "other" by using the "silent treatment."

Silence as a method of "keeping the peace" -- To what purpose? Participants forestall reconciliation without discussion to avoid embarrassment, hurt, or other perceived psychic cost. This could be the silence of feuds, topics not to be talked about, or a means of dissent. Silence can function as a chasm between a speaker and a listener: Is there more to be said? What has been left unsaid?

A paradox by noisy command: "Silence! Silence!" In a space where a speaker demands attention and has the presumed authority to insist that there be only quiet, or that only one designated person speaks. This could be a classroom, a theater, a forum... Silence! Silencio! Silence! Silenzio! No matter the language, the same inflection.

Where elders hold authority and power they may negate the tentative burgeoning thoughts of children vocalizing, met with the aphorism, "Children should be seen and not heard." There are also expressions of self-regulation: "Bite my tongue” or "Keep quiet."

There is the silence of the uninitiated, those who are unfamiliar with context: marginalized, lacking confidence, not knowing what to expect. Silence, "the absence of voice" (Belenky, et al., 1986), is the pre-cursor to "knowing," where authority imposes power, and the powerless are voiceless.

Silence as means of communication, as an alternative to speech, can be misconstrued.

"If you don't have context, [silences and pauses] can be easy to misread; mistaking a seething silence for a contented silence doesn't lead anywhere good. If you don't have an ear for them, they're easy to get wrong. In some settings, even if you're willing to hear the silences, others aren't, and they'll drown it out themselves" (Reed, 2014). 
What follows are ways of bridging discomfort in groups to allow understanding; it may take some courage to use silence as a technique to uphold voice. Yet paradoxically, on some occasions, by lessening noise, more can be heard.

\section{$\underline{\text { Situations of educational silence }}$}

Walking into a classroom on the first day of classes often presents a picture of students as separate continents: slumped in seats against the back and sides of the room, looking at their cell phones, making no effort to engage another student. It is quiet, the silence of the uninitiated.

Only when the instructor comes in, starts to call roll, are voices heard: "Present," "here" or if asked, “yes, it's pronounced that way," or "it's pronounced [this way].” It is up to the instructor to engage the students. It is tacitly understood that the instructor is the authority because in most classrooms from earliest schooling, the teacher has the singular authority to speak. In the classroom setting, for an instructor to want to engage students, to hear their voices, this may not be simple. Boniecki and Moore (2003) note:

One way instructors can facilitate active learning is to challenge the class periodically with relevant questions and encourage students to offer questions and comments. However, instructors may avoid this form of classroom interaction because of a phenomenon we call "the silence," the uncomfortable time following the instructor's question when no one responds. The silence is a particular problem in large classes in which students feel relatively anonymous and are reluctant to participate. Instructors can use a variety of techniques to combat the silence, such as waiting out the silence, calling on students by name, or initiating small group discussions.

“Active learning," promulgated for several decades as a means to engage students, can be viewed as behaviors that are not "passive," understood as listening and note-taking during lecture when students are expected to be silent. As Freeman, et al., (2014) note in an analysis of 225 studies, "The active learning interventions varied widely in intensity and implementation, and included approaches as diverse as occasional group problem-solving, worksheets or tutorials completed during class, use of personal response systems with or without peer instruction, and studio or workshop course designs." Although varied, these methods of "active learning" do include the necessity for discussion, for example in group problem-solving, and thus engagement with others. 
The Peer-Led Team Learning (PLTL) model is designed for the engagement of learners, those learning to grapple with course content in small groups led by a student Peer Leader. There are, within most groups, possibly introverts who hesitate to speak, who in their shyness do not share their knowledge. Who else may be silent participants? Women who may not trust their knowledge or voice: "Women harbor more self-doubt and questions about capabilities and intellectual competence than men do" (Gallos, 2001, p. 106), especially in fields where they have not been well-represented. Unprepared students are silent, and their lack of participation must be noticed by the Peer Leader (Rekuski, 2001).

Silent participants are a great concern in another method of engaging students in discussion, Problem-Based Learning (PBL), used often in medical and healthcare training. PBL relies on students preparing and contributing their knowledge to a "problem" - a multi-faceted example that is not easily solved by one person. Silent participants are noticeable because of PBL's focus on drawing out participants' knowledge to add to the group's understanding. In a course in physiotherapy (physical therapy) in Australia, examination of silent participants through videotaping and interviews (Remedios, Clarke, and Hawthorne, 2008) shows similarities to some reluctant participants in PLTL workshops. In interviews, the silent participants described myriad reasons for their noticeable silence.

The transition to tertiary education where the student is apprehensive about offering the wrong information, seeing oneself as having less knowledge than other students;

Lack of motivation to study outside the classroom because the student expects to be told what to do, based on prior schooling experiences;

Outside commitments: Where a student is expected to share family responsibility, care for siblings, having work commitments, there is difficulty finding time to study;

Language: Where English is the second language in the household; or English is studied as a second language; where students only understand about half of what is said and are not comfortable with colloquial (Australian) English, thus not comfortable speaking; where a student compensates by preparing materials and providing a mini-lecture during the PBL session;

Culturally embedded nature of the cues signifying the space to speak: "A common consequence was that other students spoke up before [the student] has a chance to organize or frame her input” (p. 209);

Pace: A student may not understand others' reasoning, especially when several people are speaking at once and when discussion is rapid; 
Taking longer processing time: "Most of the time, by the time I think about it, somebody else has already said it" (p. 211).

Lack of confidence in one's ability to work with the complexity of the material and a feeling of intimidation in the presence of peers: "I just felt like the nine of them possess so much knowledge that I lack" (p. 209);

Speaking feels difficult: When a student is soft-spoken and may not be heard by other group members; a preference for listening rather than verbalizing may be a way to overcome the difficulty to weed out 'noise' and distraction from the chat in order to clarify what needs to be learned.

The expectation of active engagement, visible by the participative nature of discussion, "making connections with other people's input as a way to construct coherent and collaborative group knowledge" (p. 210) may not have been explained as a condition of PBL. As a result, the difficulty of speaking in a collaborative setting made active learning by silent participants invisible. "Tutors may come to perceive their jobs as facilitating student speaking rather than as facilitating their learning... we argue that behaviour such as silence should not be viewed as direct evidence of failure to learn" (Remedios, et al., 2008, p. 212).

The active involvement of the learner in constructing their own understanding is true of the Facilitator/Peer Leader as well, by becoming aware of one's own assumptions of why students may not participate in group learning sessions. The following exercise can help develop a sensitivity or awareness as to why a student might be withdrawn.

Facilitation Exercise: Why Is This Student Quiet?

Developed by Andrea McWilliams and AE Dreyfuss (2018)

1. Participants are divided evenly into two groupings (A or B). There may be multiple pairings of groups. A minimum of four participants forms two groups of two; there is no maximum limit as participants are divided into smaller groups of two to six participants.

2. Each pairing of groups is provided with a profile, either of Student 3A or Student 3B.

3. Ask group members to read the profile provided to them, then individually write three words, phrases, or sentences to describe their student profile. Allow two minutes for the individual writing. 
4. Ask group members to share with each other what they wrote of the student profile. What are the commonalities? What are the differences? Allow one minute for each participant.

5. Each group chooses a reporter to report on their discussion in the next step. The discussion can also be written (newsprint, blackboard, whiteboard, or paper).

6. The paired groups are joined together, having discussed the profile of Student 3A or Student 3B.

\section{Profile: Student $3 \mathrm{~A}$}

This student is quiet and often comes to workshop with an attitude that conveys they do not want to be there. When assigned practice problems to work on, the student attempts the problem but gives up easily. Although the student attends every workshop and turns in all homework assignments on time, their understanding of the course content does not improve throughout the semester.

\section{Profile: Student 3B}

I attended a poorly-funded public high school that continuously fails to meet state testing standards. My junior year of high school, my chemistry teacher left at the start of the year and the administration took months to find a certified replacement. We spent the majority of the year with a long-term substitute teacher who was unable to teach chemistry. This is my third time taking chemistry in college. The first two times I failed the course and was placed on academic probation. Because of this, I was unable to receive federal student aid and I'm worried about how I will cover my tuition this semester. Although I know that obtaining a college degree is important, I'm beginning to feel like college is not for me.

7. Open discussion (all participants): What assumptions were made regarding Student 3 in each group's discussion? (The profiles A \& B are two views of the same student, as viewed externally by behavior or internally by personal experience.)

- What might a Peer Leader do to support this student?

- What can workshop group members do to support this student?

○ How might the student's situation, bounded by silence, be improved without embarrassing the student and helping the student feel welcome? 


\section{Facilitation Exercises: Icebreakers}

The goal for the first workshop session of the semester is to encourage all participants to feel welcome. To start the conversation and include all participants in a small group session, "breaking the ice" (chopping into the silence) is necessary. What about breaking the ice silently?

Silent Icebreaker I

Developed by Mitsue Nakamura

- Silent interview: In pairs, interview and find out all you can about your partner, including two interesting common facts about each other using only nonverbal communication.

- Using voice, share with the whole group what you learned about your partner, using one of the common facts (leave the other fact for your partner to share).

Observations:

- When we implemented this icebreaker during a workshop with students, they used laptops, tablets and smartphones to communicate with their partner.

- When we implemented this icebreaker during a workshop with faculty and staff, they used gestures, visual observations of each other, and pen and paper.

It is interesting to observe that the younger generation used technologies, and the older generation used what they are physically equipped with, their hands, eyes, and simple tools.

Silent Icebreaker II

Dreyfuss (2017)

- In Pairs - working in silence

- Individually write on a sheet of paper: Your name, and by writing and drawing, consider: "What does silence mean? Why are people silent?"

- Share with your partner: explain your meaning by writing

- Write questions and answers

- Make a Tent card with your partner's name for those at your table/in your group. Facilitation of a workshop group is a challenging skill, especially when group members prefer not to participate. As Brookfield (2017) notes, there are periods of silence that occur while working in groups, from introverts, those for whom English is a second language, or 
whose cultural background does not encourage voicing views. Privileging silence, on the other hand, provides time for reflection, to make cognitive connections, or rehearse what to say. "Wait on a Response" (McWilliams, et al., 2019, p. 23) introduces intentional silence, by encouraging the Peer Leader to pause at least 30 seconds so that students think about a question before talking, which allows silence to be viewed as a necessary part of the conversational rhythm. Explaining that this procedure will be used may encourage students to feel more confidence in developing and voicing their questions, concerns, and responses.

Dealing constructively with silence, drawing even the quiet and reluctant students into engagement through visual and stimulating techniques, can be accomplished through a deliberate silent exercise. "Chalk Talk" (McWilliams, et al., 2019, p. 35) adapts Brookfield's (2017) exercise to privilege silence, and in this case, promotes developing conceptual connections visually through lines, comments, and other written expressions, "marginalia." Drawing lines connecting ideas on a shared surface, such as different parts of the board or newsprint, promotes an awareness of synthesis, which is harder with verbalizing to connect with earlier comments. This might also be used with a shared document online.

\section{Facilitation Exercise: Drawing Discussion}

(Dreyfuss, 2017, based on Brookfield, 2017)

A mix of silence and smaller group discussion allows the development of conceptual understanding in this exercise.

[Materials needed: newsprint, paper, markers, tape]

Facilitator/Peer Leader: Writes Question (see Note below) on newsprint or on the board.

- Provides the following instructions, designates the grouping, and keeps track of timing.

Participants:

1. Each person creates a drawing on paper in response to Question, working individually for five minutes.

2. Convene in small groups (two to four participants) and explain drawing to the other group members, each in turn:

Discuss: How do images connect or contradict each other?

3. After discussion, each group works on a collective drawing incorporating aspects of each individual's drawing. 
4. One participant in each group is chosen as SCRIBE who takes notes on what the group is attempting to communicate.

5. Groups' images are displayed around room with blank paper next to each group drawing.

6. Participants tour gallery and comment, pose questions and write reactions on the blank sheets; use images.

7. Whole group reconvenes and participants can ask different groups about their postings.

8. Scribes take the lead in responding to questions.

Note: Questions posed could include any conceptual idea such as: How do we know a theory has explanatory power? How can photosynthesis be explained visually? What constitutes a proof? Are human beings by nature good?

The Peer Leader, in explaining why a chosen technique is being used, makes their facilitation transparent and helps those who have not felt comfortable speaking to participate more fully in the workshop session. A facilitation technique that uses both silence and movement to promote better understanding of concepts is "Stand Where You Stand" (McWilliams, et al., 2019, p. 57). The facilitator or Peer Leader initially asks students individually to write their knowledge, understanding, or application of an idea, concept, issue, or problem. The Peer Leader posts four signs in opposite corners of the space: Strongly Agree, Partly Agree, Strongly Disagree, Partly Disagree. Students are asked to stand near the sign that most closely approximates their position after their reflection through writing. One person in each position states the reason for their choice of position. Participants can move to another position after hearing others' choices and arguments. As students acquire new information and develop new understanding, they can move to different physical spaces. This exercise underscores the idea that changing one's mind because of new data, or a better argument is a sign of strength.

What about silence online? Armstrong (2020) adapted "Silent Meeting" from practices in some companies, intended to ensure that all participants are prepared for further discussion. 
Facilitation Exercise: Silent Meeting (Online)

Adapted from Armstrong, 2020

Facilitator/Peer Leader:

- Prior to the synchronous meeting time, prepares a set of questions relating to the topic or concept to be discussed.

- At the beginning of the meeting provides reading material (or problems) to participants and asks them to read the material by themselves.

Participants read the material.

Facilitator/Peer Leader: Using a shared document, poses the questions and invites written responses from participants. This posing of questions may be sequential.

Participants add their ideas to the shared document.

Facilitator/Peer Leader: Opens the discussion to verbal interaction and encourages silent interaction as well using chat or continued comments on the shared document.

Notes: A large workshop group can be rearranged into smaller groups of three to five students which receive their own problem or reading. Using workshop time to allow reading time allows for participants to be on an even footing in terms of prior preparation. The Facilitator/Peer Leader can send the materials and questions to each group the day before the workshop session.

The shared document(s) is then available for responses during the workshop session, and also provides a transcript that can be examined at a later time. As Armstrong (2020) states,

The students' notes in the silent-meeting documents offer a transcript we could return to for guidance and inspiration as we prepared for exams, developed paper ideas, and guided future discussions. Threads in the margins of the main discussion often invited further exploration, as students noted areas of the course material that they found interesting and wanted to explore further. This record from the silent meetings was at once a set of discussion notes for students and a built-in survey for me as I sought to understand what excited students about the course.

The need for confidentiality

In the first preparation meeting of the semester with Peer Leaders, one aspect of facilitation of a group needs emphasis. Peer Leaders, when later discussing what worked and what did not to make their workshop a learning forum, are cautioned not to name their students even when frustrated. This caution pertains to all students, silent as well as dominant. 
This is not to say that the issue of silence or volubility cannot be addressed, but the students themselves are not named. Peer Leaders are peers, and likely to have fellow students in other classes. Not talking about individuals and what they did or did not do in a team setting outside of that setting is a boundary to be observed by facilitators.

\section{$\underline{\text { Conclusion }}$}

Silence, rather than being problematic, can become a useful means to include all students in the workshop sessions through facilitation exercises such as presented here. Using the void of noise allows those who may feel like outsiders to find their voice, at first silently and then with sound. Peer Leaders and other facilitators of small groups, by providing alternatives to voiced discourse, will enable participants to share their thinking and enrich their team's understanding of what is to be learned.

\section{References}

Armstrong, B. (2020). To spark discussion in a Zoom class, try a "Silent Meeting." The Chronicle of Higher Education. Downloaded on November 19, 2020, from https: / / www.chronicle.com/article/to-spark-discussion-in-a-zoom-class-try-a-silent-

meeting?utm_source=Iterable\&utm_medium $=$ email\&utm_campaign $=$ campaign_17329 48_nl_Academe-

Today_date_20201119\&cid=at\&source=ams\&sourceId=4259372\&cid2=gen_login_ref resh

Belenky, M.F., Clinchy, B.M., Goldberger, N.R., \& Tarule, J.M. (1986). Women's ways of knowing: The development of self, voice, and mind. New York, NY: Basic Books.

Boniecki, K.A., \& Moore, S. (2003). Breaking the Silence: Using a Token Economy to Reinforce Classroom Participation. Teaching of Psychology, 30, 3, 224-227.

Brookfield, S. (2017). Creative approaches to stimulate classroom discussions. In Watts, L.S. \& Blessinger, P. (Eds.), Creative Learning in Higher Education: International Perspectives and Approaches. New York, NY: Routledge.

Dreyfuss, A.E. (2017). Quiet Participation: Techniques of engagement. Workshop Handout. Peer-Led Team Learning International Society Sixth Annual Conference, June 1, Northeastern Illinois University, Chicago, Illinois. 
Dreyfuss

Freeman, S., Eddy, S.L., McDonough, M., Smith, M.K., Okoroafor, N., Jordt, H., \& Wenderoth, M.P. (2014). Active learning increases student performance in science, engineering, and mathematics. PNAS, 111, 23, 8410-8415. https: / / doi.org/10.1073/pnas.1319030111

Gallos, J.V. (2001). Gender and Silence: Implications of Women's Ways of Knowing. In Roth, V., Goldstein, E., Marcus, G. (Eds.). Peer-Led Team Learning: A handbook for team leaders. Upper Saddle River, N.J.: Prentice Hall.

McWilliams, A., \& Dreyfuss, A.E. (2018). Challenging Implicit Bias: Creating a Comfortable Learning Environment for All Students. Workshop Handout. Peer-Led Team Learning International Society Seventh Annual Conference, May 31, University of Texas at Dallas, Richardson, Texas.

McWilliams, A., Dreyfuss, A.E., \& Becvar, J.E. (2019). Facilitating team-based learning: A Peer Leader's guide to leading learning activities. El Paso, TX: PLTLIS Press. (www.pltlis.org)

Reed, M. (2014). Listening for the Silences. Inside Higher Ed. Downloaded from http: / / www.insidehighered.com/blogs / confessions-community-collegedean/listening-silences\#ixzz34LdROmuI.

Rekuski, R. (2001). Helping a group that won't talk much. In Roth, V., Goldstein, E., Marcus, G. (Eds.). Peer-Led Team Learning: A handbook for team leaders. Upper Saddle River, N.J.: Prentice Hall.

Remedios, L., Clarke, D., \& Hawthorne, L. (2008). The silent participant in small group collaborative learning contexts. Active learning in higher education, 9, 201-216. 